\title{
Efficacy of Desarda's in Comparison to Lichenstien's Techniques for Primary Inguinal Hernia Repair Regarding to Operative and Post-operative Parameters
}

\author{
Abd-El-Aal Ali Saleem ${ }^{1, ~ *, ~ I s l a m ~ A h m e d ~ A m e r ², ~ E m a d ~ G o m a a ' ~}$ \\ ${ }^{1}$ Department of General Surgery, Faculty of Medicine, Sohag University, Sohag, Egypt \\ ${ }^{2}$ Department of General Surgery, Maxillofacial head and neck unit, Faculty of Medicine, Sohag University, Sohag, Egypt \\ Email address: \\ dr.abdelaal@yahoo.com (Abd-El-Aal A. S.) \\ ${ }^{*}$ Corresponding author
}

To cite this article:

Abd-El-Aal Ali Saleem, Islam Ahmed Amer, Emad Gomaa. Efficacy of Desarda's in Comparison to Lichenstien's Techniques for Primary Inguinal Hernia Repair Regarding to Operative and Post-operative Parameters. Journal of Surgery. Vol. 9, No. 3, 2021, pp. $134-144$. doi: $10.11648 /$ j.js.20210903.17

Received: April 20, 2021; Accepted: May 25, 2021; Published: May 31, 2021

\begin{abstract}
Background: The aim was to assess the efficacy and safety of Desarda's no-mesh repair in comparison to Lichtenstein's tension -free mesh repair in treatment of primary inguinal hernia. Methods: a prospective study of 80 patients suffering from unilateral primary inguinal hernia who underwent elective operation for hernia repair. The patients were of both males and females their age ranged from 20 - 60 years. They were divided into two groups (A and B). Group A: 40 patients were subjected to Desarda's no mesh repair. Group B: 40 patients were subjected to Lichtenstein's tension free mesh repair. The data were collected within one year including sociodemograghic data, general and local examination, co-morbidities, type and duration of inguinal hernia, type of operation, intra- and post -operative parameters, hospital stay and recurrence. Results: Demographic parameters, general examination, duration, type of hernia and co-morbidities in the two intervention arms were similar and shows insignificant difference. 35.5 minutes was the operative time in Desarda's group and 46 minutes in Lichtenstein's group which was highly significant $(\mathrm{p}<0.0001)$. Post-operative pain, loss of sensation over groin, chronic inguinal pain ( $>1$ month), hospital stay duration and return to normal activity were significantly decreased in Desarda's group in comparison to Lichtenstein's group $(\mathrm{P}<0.0001 \& \mathrm{P}<0.01 \& \mathrm{P}<0.01 \& \mathrm{P}<0.0001, \mathrm{P}<0.001$, respectively). Foreign body sensation and reaction, abdominal wall stiffness and migration of mesh occurs only in Lichtenstein's group. Hematoma, seroma, scrotal edema, surgical site infection and fever shows insignificant deference between the studied groups but more prevalent in Lichtenstein's group than Desarda's group ( $\mathrm{P}=0.49 \& \mathrm{P}=0.26 \& \mathrm{P}=0.21 \& \mathrm{P}=0.09$ and $\mathrm{P}=0.67$, respectively). No recurrences of hernia in both studded groups through 1- year follow-up. Conclusion: This study has shown that Desarda's repair for primary inguinal hernia gives better results when compared with the Lichtenstein's repair. It is easy to learn and it is physiologically sound. It is associated with less operative duration and mesh related complications. It can be used in a contaminated surgical field, in young individuals and in cases of financial constraints.
\end{abstract}

Keywords: Desarda's Technique, Lichtenstein's Technique, Primary Inguinal Hernia

\section{Introduction}

A hernia is defined as protrusion of whole or a part of a viscous through the wall that contains it [1]. Hernia is the most commonly seen condition in the outpatient departments in most parts of the world. Better understanding of the anatomy and physiology of the inguinal canal and improvements in surgical techniques have significantly improved outcomes for many patients [2]. Successful surgical repair of inguinal hernia depends on a tension-free closure of hernia defect to attain the lowest possible recurrence rate [3]. Several techniques have been employed in the treatment of inguinal hernias, since Bassini first described his method from tissue repairs such as modified Bassini, Shouldice,, Halsted-Tanner, McVay and Nylon-Darn to the tension-free hernioplasty that involves the use of a mesh implant over the past 20 years. 
surgery of hernia has become increasingly more complex not only due to the introduction of novel endoscopic but also conventional techniques [4]. The ideal method for modern hernia surgery should be simple, safe, tension free, permanent and cost effective, however, The choice of a method depends on the surgeon [5]. Despite the various modalities available for treatment of this common condition, no surgeon has ideal results. Complications like postoperative pain, nerve injury, infection, and recurrence continue to pose a challenge, this necessitates the introduction of a new technique for repair of hernia with reduced complication rates [6]. The Desarda's technique for repair of inguinal hernia is an improvement as it overcomes the challenges faced with the use of tension tissue-repair and mesh repair techniques. It is based on the concept of providing a strong, tension-free and physiologically dynamic posterior inguinal wall [5].

The aim of this study was to compare the Desarda's nomesh repair with Lichtenstein's tension-free mesh repair in treatment of primary inguinal hernia.

\section{Patients and Methods}

This prospective observational study of 80 patients suffering from unilateral primary inguinal hernia who were admitted to the department of general surgery in Sohag University Hospitals - Egypt. In a period from $1^{\text {st }}$ of June 2019 to $30^{\text {th }}$ March 2020. The diagnosis based on history, clinical examination and sonar. Those patients were from both sexes (male and female) and their age ranged from 20 to 60 years suffering from unilateral reducible primary inguinal hernia.

\subsection{Inclusion Criteria}

a. Aged $20-60$ years.

b. Patient with unilateral reducible primary inguinal hernia.

\subsection{Exclusion Criteria}

a. Associated surgical pathologies where the patient was getting operated for both conditions at the same time.

b. Old age with thinned out external oblique aponeurosis.

c. Pregnancy.

d. Children.

e. Morbid obesity

f. Recurrent inguinal hernia.

g. Complicated inguinal hernia.

h. Uncontrolled diabetes or hypertension.

i. Patients with bleeding disorders.

Patients were randomly subjected to Desarda's no-mesh repair and Lichtenstein's tension-free mesh repair after obtaining informed written consent which was taken from each patient after receiving an explanation of the study protocol, including the methods of operations. All patients were divided into 2 groups:

Group A: 40 patients who underwent Desarda's repair.

Group B: 40 patients who underwent Lichtenstein's repair.
Data for each patient was collected by us and our residents in department of general surgery. The collected data includes socio-demographic data:- age, sex, marital status, occupation or job, special habits and residence, Duration of hernia [in months], Type of hernia [Indirect or Direct]. Date of admission, date of discharge and duration of hospital stay, General examination and Vital signs [Pulse, blood pressure, temperature, Respiratory rate], Co- morbidities [Hypertension, Diabetes, COPD, CRF, BMI $>30 \mathrm{Kg} / \mathrm{m}^{2}$ and Smoking], Intra-operative Parameters [Type of anesthesia, duration of surgery (in minutes) and intra-operative complications], Post-operative Parameters: [Groin pain (in days) according to V A S, hematoma, seroma, scrotal edema, fever, surgical site infection according to CDC classification and grading, foreign body sensation, abdominal wall stiffness, foreign body reaction (Meshoma), fistula formation, loss of sensation over the groin, chronic inguinal pain ( $>1$ month), testicular atrophy, return to normal activity, migration of mesh and follow up for recurrence (at 3 months, at 6 months and at 1 year) after operation]. All surgeries were done by experienced surgical team, so surgical performance not varied in this series.

\subsection{Surgical Procedure}

All patients were given one shot of antimicrobial prophylaxis (1g 1st generation cephalosporin IV $30 \mathrm{~min}$. before surgery). All operations were carried out under spinal anesthesia.

\subsubsection{Desarda's No Mesh Repair}

a. This is a relatively new method based on the concept of providing a strong, mobile and physiologically active posterior inguinal wall [6].

b. This method was introduced by Dr. Mohan P. Desarda at Poona Hospital and Research Centre, Pune.

1) Anesthesia: Spinal anesthesia.

2) Desarda's repair was performed as it was originally described in 2001 [6].

3) Incision: Oblique inguinal incision made about 1.5 $\mathrm{cm}$ above and parallel to the medial two thirds of the inguinal ligament.

4) Steps: The external oblique Aponeurosis (EOA) is incised along its fibers, the inguinal canal is opened. Suturing of The medial leaf of the EOA to the inguinal ligament from the pubic tubercle to the deep ring by continuous non-absorbable suture (2/0 Prolene). Sutures are taken to narrow the deep ring, but care should be taken not to constrict the spermatic cord. A splitting incision is made in the sutured medial leaf and is extended medially up to the rectus sheath and laterally 1-2 $\mathrm{cm}$ beyond the deep ring. The width of the strip 1.5$2 \mathrm{~cm}$. The medial insertion and lateral continuation of this strip is kept intact through which it gets its blood supply. The upper free border of the strip is sutured to the conjoint tendon with $2 / 0$ prolene (polypropylene) interrupted sutures. The strip of EOA is placed behind the cord to form a new posterior wall of the inguinal 
canal. The newly formed medial leaf of the EOA is sutured to the lateral leaf of the EOA in front of the cord. Approximation of the newly formed medial leaf to the lateral leaf without tension by undermining on both surfaces of the newly medial leaf. Then closure of the wound (superficial fascia and the skin) as usual.

\subsubsection{Mechanism of Action}

External Oblique Muscle contraction produces a lateral tension in the strip, whereas internal oblique/conjoined muscle contraction results in a supero-lateral tension, this making the strip like a shield which prevents herniation. When there is a blow to the abdomen, there is a strong contraction of the abdominal muscles. This gets translated into an increased tension in the external oblique aponeurosis strip which protects from herniation. Advantages are no suture line tension, no foreign material, simple and easy to do and learn [5].

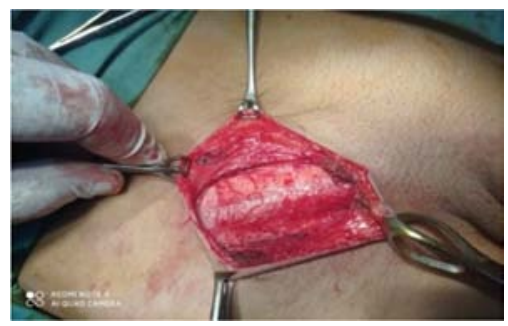

Figure 1. External oblique aponeurosis appearance before splitting

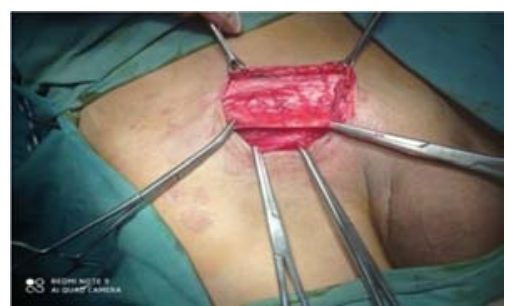

Figure 2. Upper medial leaves of external oblique aponeurosis.

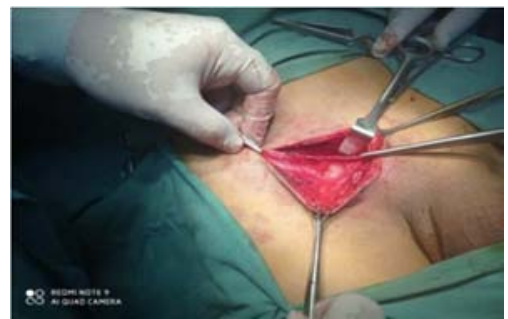

Figure 3. Lower lateral leave of external oblique aponeurosis.

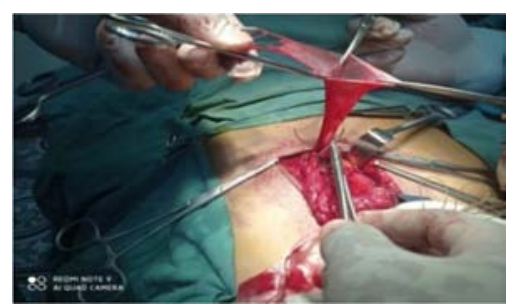

Figure 4. Trasfixation of the sac at its neck for excision.

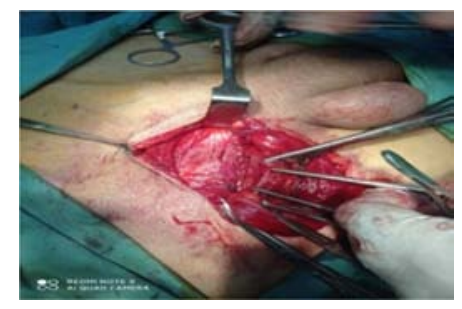

Figure 5. Medial leaf sutured to inguinal ligament.

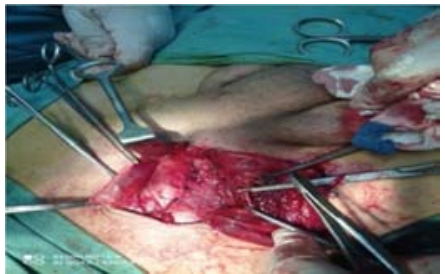

Figure 6. Upper border of EOA strip sutured to conjoint tendon.

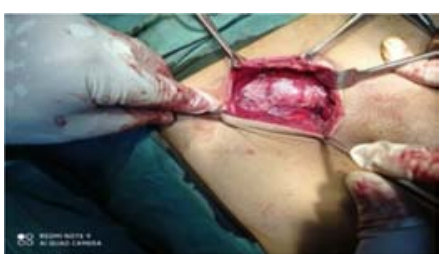

Figure 7. Desarda's repair final appearance.

\subsubsection{The Lichtenstein Tension-free Mesh Repair}

The Lichtenstein repair was performed as described by Amid [7].

In Lichtenstein's hernioplasty, an $8 \times 12 \mathrm{~cm}$ polypropylene mesh (Prolene; Ethicon) was used for all patients, mesh was trimmed to a foot-like shape to fit the inguinal floor. The fixation of mesh starting medially at the pubic bone. Ensure that medially the mesh covers the pubic bone by at least $2 \mathrm{~cm}$ because this is where most recurrences are seen [The medial most stitch fixed the mesh $2 \mathrm{~cm}$ medial to the pubic tubercle, where the anterior rectus sheath inserts into the pubic bone]. Then anchor the mesh on the inguinal ligament with a nonabsorbable continuous Polypropylene 2/0 (Prolene; Ethicon) suture up to the deep inguinal ring, it is important not leave any gaps along the inguinal ligament since this heightens the risk of recurrence. At the deep inguinal ring place the superior tail of mesh over the inferior tail with a nonabsorbable suture, first suture both tails together and then anchor both tails on the inguinal ligament. Cranially using an absorbable suture (2/0 Maxon; Covidien) to anchor the superior part of the mesh on the internal oblique. The nerve was preserved in all cases.

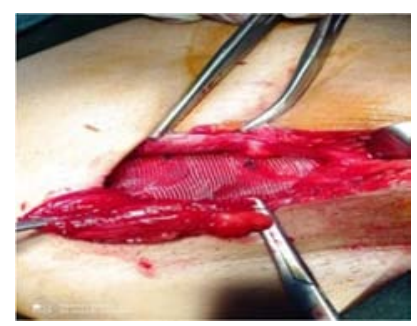

Figure 8. Lichtenstein's repair final appearance. 


\section{Ethical Consideration}

A written informed consent was taken from all participants patients or their legal guardians. Ethical approval was obtained from the medical research ethics committee under IBR Registration number: S20-158.

\section{Statistical Analysis}

Data was analyzed using STATA version 14.2 (Stata Statistical Software: Release 14.2 College Station, TX: StataCorp LP.). Quantitative data was represented as mean, standard deviation, median and range. Data was analyzed using student t-test to compare means of two groups. When the data was not normally distributed Mann-Whitney test was used. Qualitative data was presented as number and percentage and compared using either Chi square test or fisher exact test. Graphs were produced by using Excel or STATA program. P value was considered significant if it was less than 0.05 .

\section{Results}

This prospective study represents one year follow-up of two groups of patients. Group A: 40 patients who underwent Desarda's repair, they include $36(90 \%)$ males and $4(10 \%)$ females. Group B: 40 patients who underwent Lichtenstein's repair, they include $34(85 \%)$ males and $6(15 \%)$ females. Regarding to socio-demographic data:- Gender, social status and special habits were shown insignificant difference between the two studied groups, also there were more men than women (70 males vs 10 females) in both studied cohorts., as shown in table 1 .

\subsection{Age Incidence}

The age of patients ranged from 20 to 60 years in both studied groups. Regarding to group A: $14(35 \%)$ patients between age 36-45 and 12 (30\%) patients between age group 20-25. While $10(25 \%)$ patients between age 26-35 and also $10(25 \%)$ patients between age group $46-55$ in group B. The mean age of group A was $38.2 \pm 13.34$ years versus $39.95 \pm 13.57$ years in group B. There were significant difference $(\mathrm{P}=0.04)$ regarding to age groups between both studied cohorts, as shown in table 1.

Table 1. Comparison between the Desarda's no mesh repair and Lichtenstein's mesh repair as regard to personal characteristics.

\begin{tabular}{|c|c|c|c|}
\hline Variable & Desarda's no mesh repair $\mathrm{N}=40$ & Lichtenstein's mesh repair $\mathbf{N}=\mathbf{4 0}$ & P value \\
\hline \multicolumn{4}{|l|}{ Age/years } \\
\hline Mean \pm SD & $38.2 \pm 13.34$ & $39.95 \pm 13.57$ & \multirow[t]{2}{*}{0.46} \\
\hline Median (range) & $40(20: 60)$ & $44.5(20: 60)$ & \\
\hline \multicolumn{4}{|l|}{ Age group } \\
\hline Up to 25 & $12(30.00 \%)$ & $8(20.00 \%)$ & \multirow{5}{*}{0.04} \\
\hline $26-35$ & $2(5.00 \%)$ & $10(25.00 \%)$ & \\
\hline $36-45$ & $14(35.00 \%)$ & $6(15.00 \%)$ & \\
\hline $46-55$ & $8(20.00 \%)$ & $10(25.00 \%)$ & \\
\hline$>55$ & $4(10.00 \%)$ & $6(15.00 \%)$ & \\
\hline \multicolumn{4}{|l|}{ Sex } \\
\hline Female & $4(10.00 \%)$ & $6(15.00 \%)$ & \multirow[t]{2}{*}{0.50} \\
\hline Male & $36(90.00 \%)$ & $34(85.00 \%)$ & \\
\hline \multicolumn{4}{|l|}{ Social status } \\
\hline Married & $28(70.00 \%)$ & $26(65.00 \%)$ & \multirow{4}{*}{0.11} \\
\hline Single & $10(25.00 \%)$ & $10(25.00 \%)$ & \\
\hline Widow & 0 & $4(10.00 \%)$ & \\
\hline Divorced & $2(5.00 \%)$ & 0 & \\
\hline \multicolumn{4}{|l|}{ Special habit } \\
\hline Cigarettes smoker & & & \multirow{3}{*}{1.00} \\
\hline Absent & $24(60.00 \%)$ & $24(60.00 \%)$ & \\
\hline Present & $16(40.00 \%)$ & $16(40.00 \%)$ & \\
\hline \multicolumn{4}{|l|}{ Goza } \\
\hline Absent & $34(85.00 \%)$ & $34(85.00 \%)$ & \multirow[t]{2}{*}{1.00} \\
\hline Present & $6(15.00 \%)$ & $6(15.00 \%)$ & \\
\hline \multicolumn{4}{|l|}{ Others } \\
\hline Absent & $34(85.00 \%)$ & $32(80.00 \%)$ & \multirow[t]{2}{*}{0.56} \\
\hline Present & $6(15.00 \%)$ & $8(20.00 \%)$ & \\
\hline
\end{tabular}

\subsection{General Examination}

Regarding to pulse rate, systolic and diastolic blood pressure, temperature and respiratory rate, there were insignificant difference between both studied groups, as shown in table 2 . 
Table 2. Comparison between the Desarda's no mesh repair and Lichtenstein's mesh repair regarding to general examination.

\begin{tabular}{lll}
\hline Variable & Desarda's no mesh repair N=40 & Lichtenstein's mesh repair N=40 \\
\hline Pulse rate & & P value \\
Mean \pm SD & $74.45 \pm 3.99$ & $74.4 \pm 4.76$ \\
Median (range) & $75(68: 81)$ & $75(65: 85)$ \\
Systolic blood pressure & $118.75 \pm 13.07$ & $118 \pm 12.07$ \\
Mean \pm SD & $115(100: 140)$ & $117.5(100: 140)$ \\
Median (range) & & 0.96 \\
Diastolic blood pressure & $74 \pm 9.26$ & $75 \pm 8.58$ \\
Mean \pm SD & $70(60: 90)$ & $75(60: 90)$ \\
Median (range) & & $37 \pm 0$ \\
Temperature & $37 \pm 0$ & $37(37: 37)$ \\
Mean \pm SD & $37(37: 37)$ & 0.61 \\
Median (range) & & 1.00 \\
Respiratory rate & $17.2 \pm 1.44$ & $17.35 \pm 1.30$ \\
Mean \pm SD & $17(15: 20)$ & $16: 20)$ \\
Median (range) & & 0.62 \\
\hline
\end{tabular}

\subsection{Types of Hernia}

$32(80 \%)$ patients had indirect hernia and $8(20 \%)$ patients had direct hernia in patients who underwent Desarda's repair. While $30(75 \%)$ patients had indirect hernia and $10(25 \%)$ patients had direct hernia in patients who underwent Lichenstein's repair. So there were insignificant difference regarding to type of hernia $(\mathrm{P}=0.59)$ between the two studied groups, as shown in table 3 .

\subsection{Duration of Hernia}

8 months were the average duration of hernia in patients subjected to Desarda's repair, whereas in those who subjected to Lichtenstein's repair were 11 months. Hence, there were insignificant difference $(\mathrm{P}=0.13)$ regarding to the duration of hernia between both studied groups, as shown in table 3 .

Table 3. Comparison between the Desarda's no mesh repair and Lichtenstein's mesh repair regarding to type and duration of hernia.

\begin{tabular}{llll}
\hline Variable & Desarda's no mesh repair $\mathbf{N}=\mathbf{4 0}$ & Lichtenstein's mesh repair N=40 & P value \\
\hline Type of hernia & & & \\
Indirect & $32(80.00 \%)$ & $30(75.00 \%)$ & 0.59 \\
Direct & $8(20.00 \%)$ & $10(25.00 \%)$ & \\
Duration of hernia (ms) & & $11.95 \pm 7.18$ & \\
Mean \pm SD & $9.00 \pm 4.10$ & $11(4: 31)$ & 0.13 \\
Median (range) & $8(4: 18)$ & & \\
\hline
\end{tabular}

Table 4. Comparison between the Desarda's no mesh repair and Lichtenstein's mesh repair as regard to co-morbidities.

\begin{tabular}{|c|c|c|c|}
\hline Variable & Desarda's no mesh repair $N=40$ & Lichtenstein's mesh repair $N=40$ & P value \\
\hline \multicolumn{4}{|c|}{ Hypertension } \\
\hline Absent & $34(85.00 \%)$ & $30(75.00 \%)$ & \multirow[t]{2}{*}{0.26} \\
\hline Present & $6(15.00 \%)$ & $10(25.00 \%)$ & \\
\hline \multicolumn{4}{|l|}{ Diabetes } \\
\hline Absent & $32(80.00 \%)$ & $38(95.00 \%)$ & \multirow[t]{2}{*}{0.09} \\
\hline Present & $8(20.00 \%)$ & $2(5.00 \%)$ & \\
\hline \multicolumn{4}{|l|}{ COPD } \\
\hline Absent & $38(95.00 \%)$ & $38(95.00 \%)$ & \multirow[t]{2}{*}{1.00} \\
\hline Present & $2(5.00 \%)$ & $2(5.00 \%)$ & \\
\hline \multicolumn{4}{|l|}{ Smoking } \\
\hline Absent & $22(55.00 \%)$ & $22(55.00 \%)$ & \multirow[t]{2}{*}{1.00} \\
\hline Present & $18(45.00 \%)$ & $18(45.00 \%)$ & \\
\hline \multicolumn{4}{|l|}{ CRF } \\
\hline Absent & $40(100 \%)$ & $40(100 \%)$ & \multirow[t]{2}{*}{1.00} \\
\hline Present & 0 & 0 & \\
\hline \multicolumn{4}{|c|}{$\mathrm{BMI}>30 \mathrm{Kg} / \mathrm{m}^{2}$} \\
\hline Absent & $32(80.00 \%)$ & $32(80.00 \%)$ & \multirow[t]{2}{*}{1.00} \\
\hline Present & $8(20.00 \%)$ & $8(20.00 \%)$ & \\
\hline
\end{tabular}

\subsection{Co-morbidities}

Regarding to co-morbidities, there were insignificant difference between the two studied groups, as shown in table 4 .

\subsection{Intra-operative Parameters}

\subsubsection{Type of Anesthesia}

Both groups underwent surgery under spinal anesthesia, so 
there were insignificant difference $(\mathrm{P}=1.0)$ regarding to anesthesia between the two studied cohorts, as shown in table 5 .

\subsubsection{Duration of Surgery}

The average duration of surgery for Desarda's repair was 35.5 minutes, while for Lichtenstein's repair was 46 minutes. So, there was highly significant $(\mathrm{P}<0.0001)$ decrease in duration of surgery in Desarda's repair in comparison to Lichtenstein's repair, as shown in table 5 and figure 9.

\subsubsection{Intraoperative Complications}

Regarding to intraoperative complications, there were insignificant difference $(\mathrm{P}=1.0)$ between the two studied groups, as shown in table 5 .

Table 5. Comparison between the Desarda's no mesh repair and Lichtenstein's mesh repair regarding to intraoperative parameters.

\begin{tabular}{llc}
\hline Variable & Desarda's no mesh repair N=40 & Lichtenstein's mesh repair N=40 \\
\hline Type of anesthesia & & P value \\
Spinal & $40(100 \%)$ & $40(100 \%)$ \\
Duration of surgery (min) & $35.75 \pm 5.01$ & 47.00 \\
Mean \pm SD & $35.5(28: 45)$ & $46(38: 60)$ \\
Median (range) & & 40.30 \\
Intraoperative complication & $40(100 \%)$ & $40(100 \%)$ \\
Absent & 0 & 0 \\
Present & & 1.00 \\
\hline
\end{tabular}

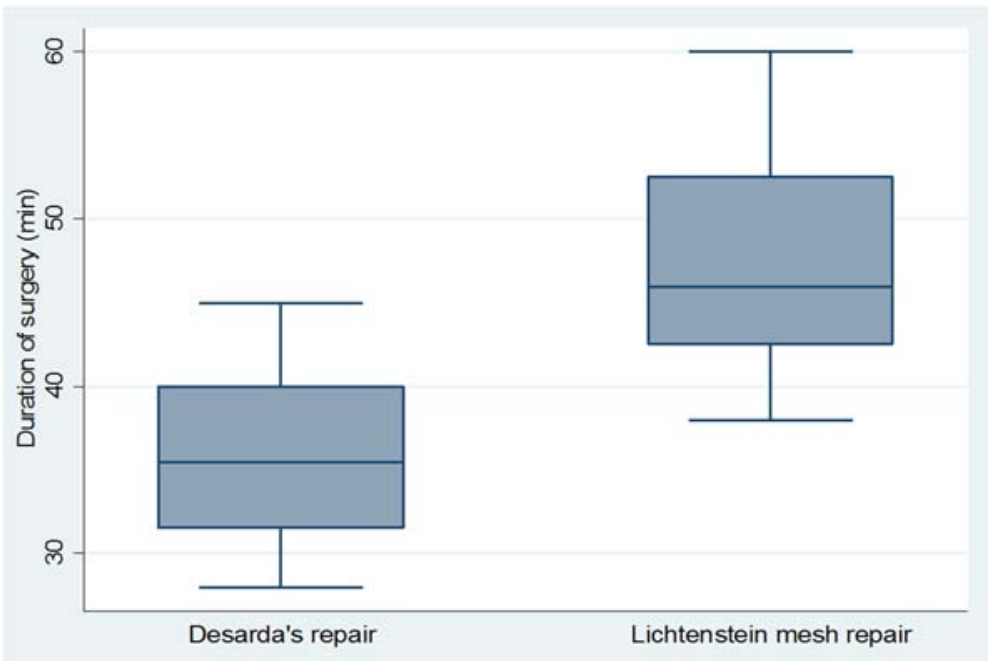

Figure 9. Duration of surgery in each group.

\subsection{Postoperative Parameters}

Table 6. Comparison between the Desarda's no mesh repair and Lichtenstein's mesh repair regarding to Post-operative parameters.

\begin{tabular}{|c|c|c|c|}
\hline Variable & Desarda's no mesh repair $\mathrm{N}=40$ & Lichtenstein's mesh repair $\mathrm{N}=\mathbf{4 0}$ & P value \\
\hline \multicolumn{4}{|l|}{ Groin pain } \\
\hline$<3$ days & $24(60.00 \%)$ & $6(15.00 \%)$ & \multirow{3}{*}{$<0.0001$} \\
\hline 3-5 days & $12(30.00 \%)$ & $22(55.00 \%)$ & \\
\hline$>7$ days & $4(10.00 \%)$ & $12(30.00 \%)$ & \\
\hline \multicolumn{4}{|l|}{ Hematoma } \\
\hline Absent & $40(100 \%)$ & $38(95.00 \%)$ & \multirow[t]{2}{*}{0.49} \\
\hline Present & 0 & $2(5.00 \%)$ & \\
\hline \multicolumn{4}{|l|}{ Seroma } \\
\hline Absent & $38(95.00 \%)$ & $34(85.00 \%)$ & \multirow[t]{2}{*}{0.26} \\
\hline Present & $2(5.00 \%)$ & $6(15.00 \%)$ & \\
\hline \multicolumn{4}{|l|}{ Scrotal edema } \\
\hline Absent & $36(90.00 \%)$ & $32(80.00 \%)$ & \multirow[t]{2}{*}{0.21} \\
\hline Present & $4(10.00 \%)$ & $8(20.00 \%)$ & \\
\hline \multicolumn{4}{|l|}{ Fever } \\
\hline Present & $2(5.00 \%)$ & $4(10.00 \%)$ & 0.67 \\
\hline \multicolumn{4}{|l|}{ Surgical site infection } \\
\hline Absent & $38(95.00 \%)$ & $32(80.00 \%)$ & \multirow[t]{2}{*}{0.09} \\
\hline Present & $2(5.00 \%)$ & $8(20.00 \%)$ & \\
\hline Foreign body sensation & & & 0.001 \\
\hline
\end{tabular}




\begin{tabular}{|c|c|c|c|}
\hline Variable & Desarda's no mesh repair $N=40$ & Lichtenstein's mesh repair $\mathrm{N}=\mathbf{4 0}$ & Pvalue \\
\hline Absent & $40(100 \%)$ & $30(75.00 \%)$ & \\
\hline Present & 0 & $10(25.00 \%)$ & \\
\hline \multicolumn{4}{|c|}{ Abdominal wall stiffness } \\
\hline Absent & $40(100 \%)$ & $32(80.00 \%)$ & \multirow[t]{2}{*}{0.005} \\
\hline Present & 0 & $8(20.00 \%)$ & \\
\hline \multicolumn{4}{|c|}{ Foreign body reaction } \\
\hline Absent & $40(100 \%)$ & $36(90.00 \%)$ & \multirow[t]{2}{*}{0.12} \\
\hline Present & 0 & $4(10.00 \%)$ & \\
\hline \multicolumn{4}{|c|}{ Fistula formation } \\
\hline Absent & $40(100 \%)$ & $40(100 \%)$ & \multirow[t]{2}{*}{1.00} \\
\hline Present & 0 & 0 & \\
\hline \multicolumn{4}{|c|}{ Loss of sensation over groin } \\
\hline Absent & $38(95.00 \%)$ & $30(75.00 \%)$ & \multirow[t]{2}{*}{0.01} \\
\hline Present & $2(5.00 \%)$ & $10(25.00 \%)$ & \\
\hline \multicolumn{4}{|c|}{ Chronic inguinal pain $(>1 \mathrm{~ms})$} \\
\hline Absent & $38(95.00 \%)$ & $30(75.00 \%)$ & \multirow[t]{2}{*}{0.01} \\
\hline Present & $2(5.00 \%)$ & $10(25.00 \%)$ & \\
\hline \multicolumn{4}{|c|}{ Testicular atrophy } \\
\hline Absent & $40(100 \%)$ & $40(100 \%)$ & \multirow[t]{2}{*}{1.00} \\
\hline Present & 0 & 0 & \\
\hline
\end{tabular}

\subsubsection{Groin Pain (in Days)}

There was highly significant $(\mathrm{P}<0.0001)$ decrease in groin pain in Desarda's repair in comparison to Lichtenstein's repair, as shown in table 6 and figure 10.

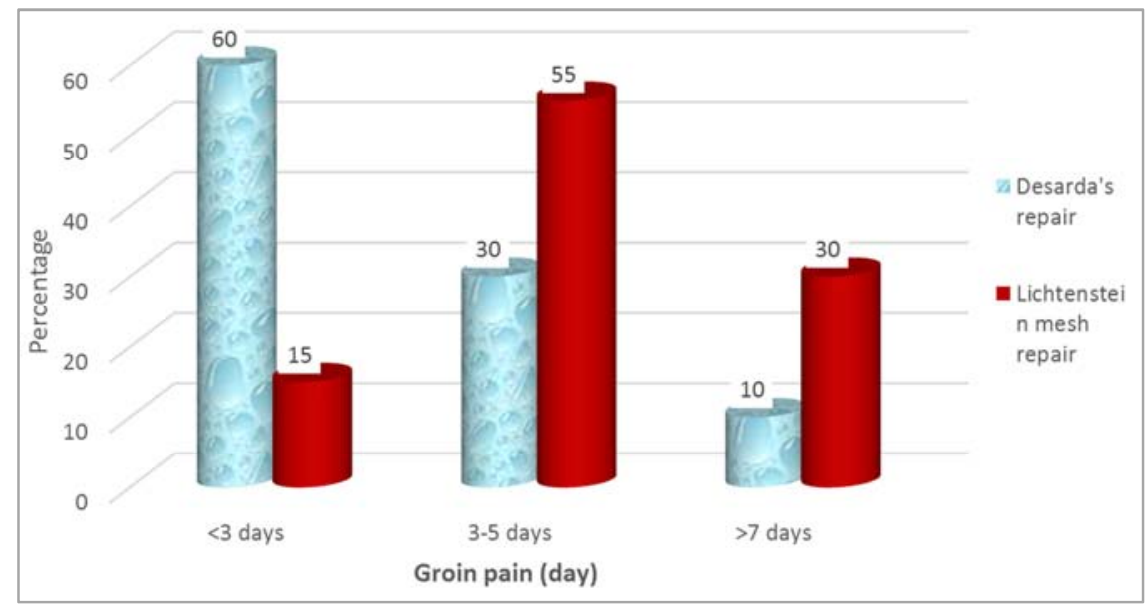

Figure 10. Incidence of groin pain in each group.

\subsubsection{Hematoma}

Of the 40 patients who underwent Desarda's repair no patients had developed hematoma, while 2 of 40 patients who underwent Lichtenstein's repair had developed hematoma, with $\mathrm{P}=0.49$ (insignificant difference) between the two studied groups, as shown in table 6 .

\subsubsection{Seroma}

Inspite of insignificant difference $(\mathrm{P}=0.26)$ between the two studied groups regarding to seroma, it was more prevalent in patients who underwent Lichtenstein's repair (6 patients $15 \%$ ) than those who underwent Desarda's repair (2 patients $5 \%$ ), as shown in table 6 .

\subsubsection{Scrotal Edema}

Regarding to scrotal edema there was insignificant difference $(\mathrm{P}=0.21)$ between both studied groups, but it was more prevalent in patients who underwent Lichtenstein's repair (8 patients 20\%) than those who underwent Desarda's repair (4 patients 10\%), as shown in table 6 .

\subsubsection{Fever}

It was shown insignificant difference $(\mathrm{P}=0.67)$ between both groups, but it was more common in patients who underwent Lichtenstein's repair (4 patients $10 \%$ ) than those who underwent Desarda's repair (2 patients 5\%), as shown in table 6 . It was mostly due to chest infection.

\subsubsection{Surgical Site Infection}

During the postoperative period patients who had surgical site infections were identified and graded as grade I according to CDC classification. $2(5 \%)$ patients in the Desarda group had surgical site infections, whereas 8 patients (20\%) had surgical site infections in the Lichtenstein group. But, insignificant difference $(\mathrm{P}=0.09)$ between the two groups were observed, as shown in table 6 and figure 11 . 


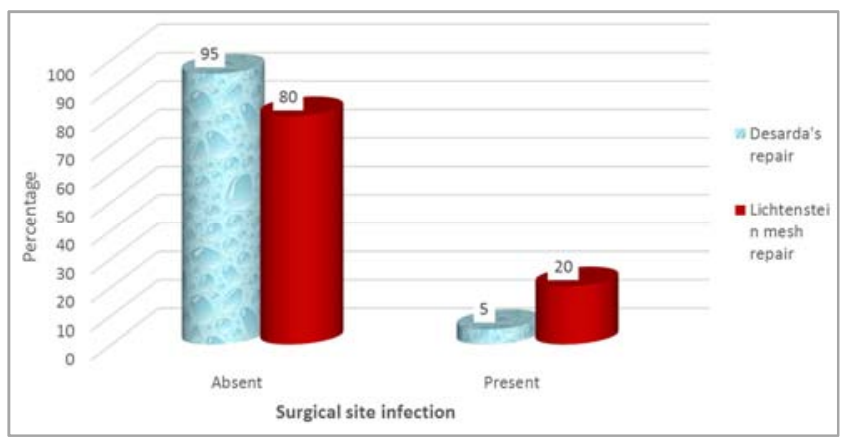

Figure 11. Incidence of surgical site infection in each group.

\subsubsection{Foreign Body Sensation}

$10(25 \%)$ patients had foreign body sensation among patients who underwent hernia repair by Lichtenstein's technique compared to Desarda's technique where there were no such incidence. There was significant $(\mathrm{P}<0.001)$ increase in foreign body sensation in Lichtenstein's technique in comparison to Desarda's technique, as shown in table 6 and figure 12 .

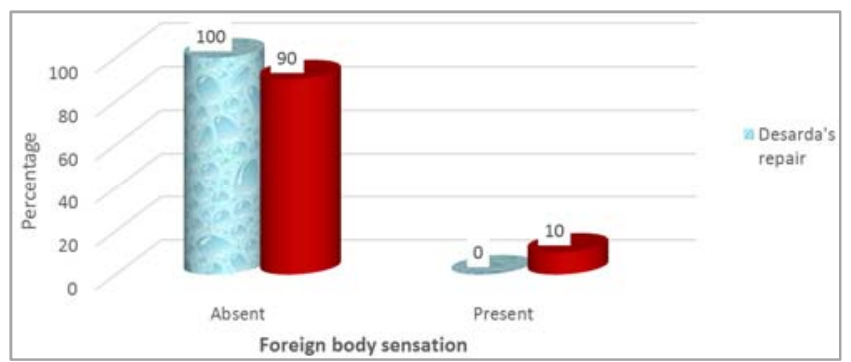

Figure 12. Incidence of foreign body sensation in each group.

\subsubsection{Abdominal Wall Stiffness}

None of the 40 patients who underwent Desarda's repair had abdominal wall stiffness, while $8(20 \%)$ of the 40 patients who underwent Lichtenstein's repair were complaining of abdominal wall stiffness. This was statistically significant $(\mathrm{P}<0.005)$, as shown in table 6 and figure 13 .

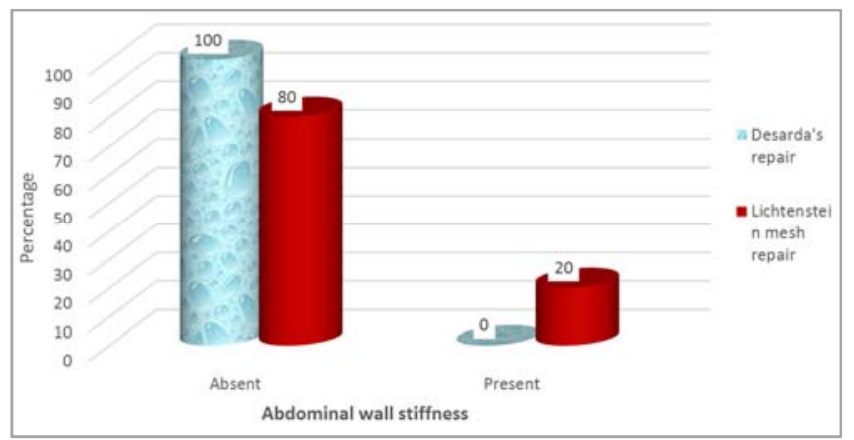

Figure 13. Incidence of abdominal wall stiffness in each group.

\subsubsection{Foreign Body Reaction}

None of the 40 patients who underwent Desarda's repair had foreign body reaction, while $4(10 \%)$ of the 40 patients who underwent Lichtenstein's repair were complaining of foreign body reaction. This was statistically insignificant
$(\mathrm{P}<0.12)$, as shown in table 6.

\subsubsection{Loss of Sensation over Groin}

$2(5 \%)$ of the 40 patients who underwent Desarda's repair were complaining of Loss of sensation over the groin, while $10(25 \%)$ of the 40 patients who underwent Lichtenstein's repair were complaining of Loss of sensation over groin. This was statistically significant $(\mathrm{P}<0.01)$, as shown in table 6 . figure 14 .

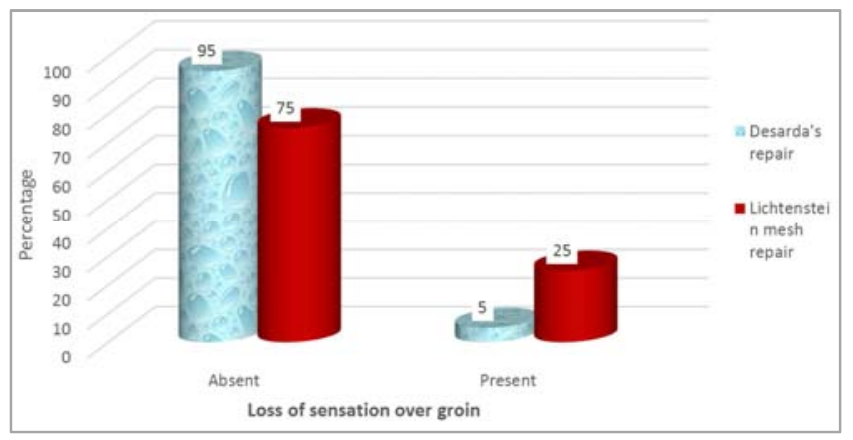

Figure 14. Incidence of loss of sensation over groin in each group.

\subsubsection{Chronic Inguinal Pain (>1 Month)}

Of the 40 patients who underwent Desarda's repair $2(5 \%)$ patients had chronic inguinal pain ( $>1$ month), while 10 $(25 \%)$ of the 40 patients who underwent Lichtenstein's repair had chronic inguinal pain ( $>1$ month). This was statistically significant $(\mathrm{P}<0.01)$, as shown in table 6 .

\subsubsection{Testicular Atrophy and Fistula Formation}

None of both studied groups suffering from testicular atrophy and Fistula formation. This were statistically insignificant ( $\mathrm{P}=1.0$ for each), as shown in table 6 .

\subsubsection{Duration of Hospital Stay (Day)}

The average duration of hospital stay was 2 days in case of Desarda's technique and 4 days in Lichtenstein's technique with a $\mathrm{P}<0.0001$ (highly significant), as shown in table 7 and figure 15 .

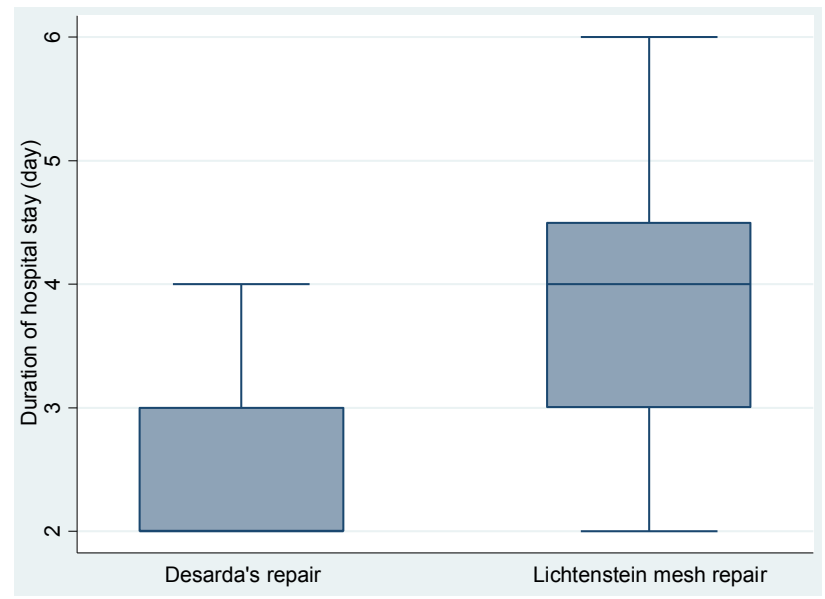

Figure 15. Duration of hospital stay (day) in each group

\subsubsection{Return to Normal Activity}

In Desarda's group, the duration to return to normal 
activity was $<7$ days in $24(60 \%)$ patients, $7-15$ days in 10 $(25 \%)$ patients, $>15$ days in $6(15 \%)$ patients. Whereas in Lichtenstein's group, the duration to return to normal activity was $<7$ days in $8(20 \%)$ patients, $7-15$ days in $20(50 \%)$ patients, $>15$ days in $12(30 \%)$ patients. So that the periods of return to normal activity had highly significant $(\mathrm{P}=<0.001)$ decrease in Desarda's group in comparison to Lichtenstein's group, as shown in table 7 and figure 16.

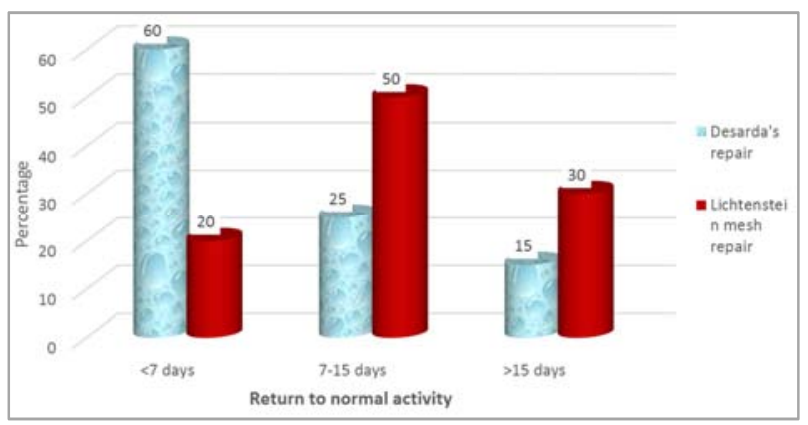

Figure 16. Return to normal activity in each group.

Table 7. Comparison between the Desarda's no mesh repair and Lichtenstein's mesh repair as regards outcome of operation.

\begin{tabular}{lll}
\hline Variable & Desarda's no mesh repair N=40 & Lichtenstein's mesh repair N=40 \\
\hline $\begin{array}{l}\text { Duration of hospital stay (day) } \\
\text { Mean } \pm \text { SD }\end{array}$ & $2.55 \pm 0.76$ & $3.8 \pm 1.01$ \\
Median (range) & $2(2: 4)$ & $4(2: 6)$ \\
Return to normal activity & & $8(20.00 \%)$ \\
$<7$ days & $24(60.00 \%)$ & $20(50.00 \%)$ \\
$7-15$ days & $10(25.00 \%)$ & $12(30.00 \%)$ \\
$>15$ days & $6(15.00 \%)$ & 0 \\
Recurrence & 0 & 0 \\
At 3 months & 0 & 0.001 \\
At 6 months & 0 & 0 \\
At 1 year & 0 & $38(95.00 \%)$ \\
Migration of mesh & & $2(5.00 \%)$ \\
Absent & $40(100 \%)$ & 0.49 \\
Present & 0 & 0 \\
\hline
\end{tabular}

\subsubsection{Migration of Mesh}

None of the 40 patients who underwent Desarda's repair had Migration of mesh, while $2(5 \%)$ of the 40 patients who underwent Lichtenstein's repair had migration of mesh, This was statistically insignificant $(\mathrm{P}<0.49)$, as shown in table 7 .

\subsubsection{Recurrence}

No recurrence in both studied groups during one year follow up, as shown in table 7.

\section{Discussion}

Inguinal hernia is a very common condition affecting mankind [8]. The main cause of inguinal hernia in most of the patients is the physiological weakness of posterior inguinal canal wall. Hence the main goal of hernia repair should be focused at providing mobile, strong and physiologically active posterior wall of the inguinal canal [9].

The distribution of demographic parameters, general examination, duration and type of hernia, co-morbidities and clinical findings in the two intervention arms of this research was similar and shows insignificant difference. This implies that the process of randomization was accurate and that any influence of these variables on the key outcomes of surgery was similarly distributed in the two study groups.

Regarding to patients age and duration of hernia, other studies found that, the incidence of inguinal hernia was highest in the $4^{\text {th }}$ decade with a mean age of 48 years. The average duration of hernia in Desarda's technique was 7 months whereas in Lichtenstein's technique it was 11 months [10]. In our study, the incidence of inguinal hernia was highest in the $3^{\text {rd }}$ and $4^{\text {th }}$ decades. The average duration of hernia in Desarda's technique was 8 months whereas in Lichtenstein's technique it was 11 months.

As regard to duration of surgery, study conducted by Mitura and Romańczuk suggested that. The Desarda and Lichtenstein techniques are similar in respect of surgery time [11]. Various studies show that Desarda's technique is associated with lesser duration of surgery [6]. Youssef et al, report that, Desarda repair had Shorter operating time [12], other studies showed that the Desarda repair takes a significantly shorter operative time [6]. Gupta A et al, reported that, Mean operative time for Desarda repair was shorter $(42.08 \pm 3.42 \mathrm{~min})$ compared to Lichtenstein repair $(49.01 \pm 4.77 \mathrm{~min})$ [13]. This concurs with our results, the Desarda's repair takes significantly shorter operative time than Lichtenstein's repair $(\mathrm{P}<0.0001)$.

Mesh repair is now commonly used and is most often referred to as the gold standard technique. But this surgery is associated with more complications like chronic groin pain, hematoma, seroma, testicular atrophy etc., mostly in the hands of less experienced junior consultants. Mesh is also costly and is not available in many parts of the world. Though mesh acts like a mechanical barrier, it does not provide a mobile and dynamic posterior wall [8]. This concurs with our results, in which post-operative complications were more prevalent among patients underwent Lichtenstein repair than those who underwent Desarda's repair. 
Groin pain has been found to be due to fibrous reaction to foreign body in case of mesh repair, leading to spermatic cord and nerve enmeshment, which affects the quality of life of the patient [8]. Comparing with other studies such as Rod- riguez et al, it showed the same result that there was insignificant difference regarding pain [6]. Also the study that has been conducted by Szopinski et al, showed insignificant difference in chronic pain that experienced by 4.8 and $2.9 \%$ of patients from Desarda and Lichtenstein groups, respectively $(p=0.464)$ [5]. Other investigators found that, the early post-operative pain (day 1 and day 7) was significantly lower in Desarda group but showed insignificant difference between both groups after 6 months [5]. Other studies reported that, early post-operative pain was lower in Desarda group however, it not reach significant level [14]. In contrast to Szopinski et al who reported that, early post-operative pain was higher in Desarda group however in another publication by them they reported no significant difference [15]. In our study we observed that, There was significant decrease in groin pain at $<3$ days, 3-5 days and $>7$ days in Desarda's repair in comparison to Lichtenstein repair $(\mathrm{P}<0.0001)$, also there was significant decrease in Desarda's repair in comparison to Lichtenstein's repair regarding to chronic inguinal pain ( $>1$ month) $(\mathrm{P}<0.01)$.

Seroma was higher after use of the Lichtenstein method and this can be explained by the influence of the synthetic mesh on surrounding tissues. This consistent with other studies and the known influence of polypropylene on tissue [16]. This concurs with our study, inspite of insignificant difference $(\mathrm{P}=0.26)$ between the two studied groups regarding to Seroma, it is more common in patients who underwent Lichtenstein's repair (6 patients $=15 \%$ ) than those who underwent Desarda's repair ( 2 patients $=5 \%$ ).

Other investigators reported that, foreign body sensation and abdominal wall stiffness were expressed by 12 to $16 \%$ of the Desarda group and 17 to $22 \%$ of the Lichtenstein group of patients at different time points. Other authors reported that, the results were within the range from $4.5-43.8 \%$ for mesh techniques [17]. In our study, there were significant increase in incidence of foreign body sensation and abdominal wall stiffness in Lichtenstein group in comparison to Desarda group ( $\mathrm{P}<0.001 \&<0.005$ respectively).

Regarding to surgical site infection, other researches observed that, surgical site infection was higher in mesh repair (10\%) when compared to Desarda's technique (0\%) [10]. Other studies reported that, after surgery in the Lichtenstein group there were 8 mesh infections. Partial excision of the mesh were required in two cases and total excision in one case. Desarda technique has lower morbidity as compared to mesh hernioplasty [5]. This concurs with our study, 2 (5\%) patients in the Desarda group had surgical site infections, whereas 8 $(20 \%)$ patients in the Lichtenstein group. But, there was insignificant difference $(\mathrm{P}=0.09)$ between the two studied groups.

Regarding to loss of sensation over the groin, others reported that loss of sensation was present only in
Lichtenstein's repair group [10]. In our presentation we found that, there was significant increase in incidence of Loss of sensation over groin in Lichtenstein group in comparison to Desarda group $(\mathrm{P}<0.01)$.

Regarding to scrotal edema and testicular atrophy, other studies reported that, none of the patients who underwent Desarda's repair had scrotal edema or testicular atrophy while $6(20 \%)$ patients in the Lichtenstein's mesh repair group had scrotal edema and $1(3.3 \%)$ patient had testicular atrophy. The $\mathrm{P}$ value was highly significant [10]. In our study we observed that, $8(20 \%)$ patients who underwent Lichtenstein's mesh repair were suffering from scrotal edema but only $4(10 \%)$ patients who underwent Desarda's repair were suffering from scrotal edema (statistically insignificant, $\mathrm{P}=0.21$ ). None of both studied groups suffering from testicular atrophy (statistically insignificant, $\mathrm{P}=1.0$ ).

None of the 40 patients who underwent Desarda's repair had foreign body reaction or migration of mesh, while 4 (10\%) of the 40 patients who underwent Lichtenstein's repair had foreign body reaction and also $2(5 \%)$ patients had migration of mesh. They were statistically insignificant $(\mathrm{P}=0.12 \& \mathrm{P}=0.49$, respectively).

Regarding to duration of hospital stay, Various studies show that Desarda's technique is associated with lesser duration of hospital stay and time to return to normal activity [5]. Postoperative stay after surgery was also significantly in favour of the Desarda group [6]. This concurs with our results, The average duration of hospital stay was 2 days in case of Desarda's technique and 4 days in Lichtenstein's technique with a $\mathrm{P}<0.0001$ (highly significant).

Various studies show that Desarda's technique is associated with lesser time to return to normal activity [5]. Other studies reported that, the mean period required for the patients to return to work in the Desarda group was 8.26 days while it was 12.58 days in the Lichtenstein group, this was statistically significant [6]. This concurs with our presentation, there was significant decrease $(\mathrm{P}<0.001)$ in a period required for the patients to return to work in the Desarda group in comparison to Lichtenstein group.

Regarding to recurrence of hernia, other researches showed a recurrence of $1.97 \%$, but it was observed during a 10 -year follow-up [18]. But other studies, found that both groups had no recurrences during 2-year follow- up [10]. In our presentation, there were no recurrence of hernia in both groups during one year follow up.

\section{Conclusion and Recommendations}

This study has shown that Desarda's no mesh repair for primary inguinal hernia gives better results when compared with the Lichtenstein's Mesh repair. It is technically simpler than the other no mesh repairs like Shouldice repair. It is easy to learn and it is physiologically sound. It is associated with less duration of surgery, early return to normal activity and less mesh related complications in the postoperative period e.g.:pain, surgical site infection, foreign body sensation, foreign body reaction, migration of mesh.... etc. It can be used in a 
contaminated surgical field, in young individuals and in cases of financial constraints.

Hence, Desarda's no mesh repair is favorably comparable with Lichtenstein's mesh repair. When compared to Lichtenstein's mesh repair produces better results.

1. So that we strongly recommend that all the surgeons get acquainted with this Desarda's technique.

2. Large scale and Long term follow up may be required to identify the recurrent cases if any.

\section{Financial Suport and Sponsorship}

Nil.

\section{Conflicts of Interest}

There are no conflicts of interest.

\section{References}

[1] Das S: A Manual of clinical surgery. S Das Publication; 2008; 38: 594.

[2] Schwartz's Principles of Surgery:- 10th edition. McGraw Hill Education; 2014; 37.

[3] Zinner MJ, Ashley SW. Maingot's Abdominal Operations. 12th ed. Boston, Massachusetts: McGraw Hill Publishers; 2018. 127.

[4] Courtney M, Townsend JR, Beauchamp RD, Evers BM, Mattox KL, eds: Sabiston Textbook of Surgery: The Biological Basis of Modern Surgical Practice. 17th ed: Elsevier Inc. 2007.

[5] Szopinski J, Dabrowiecki S, Pierscinski S, Jackowski M, Jaworski M, Szuflet Z: Desarda versus Lichtenstein technique for primary inguinal hernia treatment: 3-year results of a randomized clinical trial. World J Surg. 2012 May 1; 36 (5): 984-92.

[6] Rodríguez P, Herrera PP, Gonzalez OL, Alonso JR, Blanco HS: A randomized trial comparing lichtenstein repair and no mesh desarda repair for inguinal hernia: a study of 1382 patients. East Central Af J Surg. 2013; 18 (2): 18-25.
[7] Amid PK: Lichtenstein tension-free hernioplasty: its inception, evolution, and principles. Hernia. 2004; 8 (1): 1-7.

[8] Desarda MP: Physiological repair of inguinal hernia: a new technique (study of 860 patients). Hernia. 2006 Apr 1; 10 (2): 143-6.

[9] Desarda MP: Inguinal herniorrhaphy with an undetached strip of external oblique aponeurosis: a new approach used in 400 patients. Europ J Surg. 2001 Jun 1; 167 (6): 443-8.

[10] Prakash et al: Comparative study of open mesh repair and Desarda's no-mesh repair for inguinal hernia, in GMKMCH, Salem, India. Int Surg J. 2018 Sep; 5 (9): 3139-3145.

[11] Mitura K, Romańczuk M: Comparison between two methods of inguinal hernia surgery - Lichtenstein and Desarda. Pol Merkur Lekarski 2008; 24: 392-5.

[12] Youssef T, El-Alfy K, Farid M: Randomized clinical trial of Desarda versus Lichtenstein repair for treatment of primary inguinal hernia. Int J Surg. 2015; 20: 28-34.

[13] Gupta A, Sharma SC, Sharma JP, Singhal P. Comparison of tension free Desarda technique with Lichtenstein for inguinal hernia repair. International Surgery Journal 2019; 6 (5): 152833.

[14] Manyilirah W, Kijjambu S, Upoki A, Kiryabwire J: Comparison of non-mesh (Desarda) and mesh (Lichtenstein) methods for inguinal hernia repair among black African patients: a short-term double- blind RCT. Hernia. 2012; 16 (2): 133-44.

[15] Szczesny W, Szopinski J, Reslinski A: Early postoperative pain after Lichtenstein and Desarda hernioplasty. Polish Surg. 2010; 12: 67-75.

[16] Horstmann R, Hellwig M, Classen $C$ et al: Impact of polypropylene amount on functional outcome and quality of life after inguinal hernia repair by the TAPP procedure using pure, mixed, and titanium-coated meshes. World J Surg.; 2006. 30: 1742-1749.

[17] Staerkle RF, Buchli C, Villiger P: Patient satisfaction, hernia recurrence rate, and chronic pain 10 years after endoscopic total extraperitoneal inguinal hernia repair. Surg Laparosc Endosc Percutan Tech.; 2009. 19: 405-409.

[18] Desarda MP: Surgical physiology of inguinal hernia repair-a study of 200 cases. BMC Surg. 2003 Dec; 3 (1): 2. 